\section{David Moreno Villalobos ${ }^{1}$ Ditel Paniura Rodríguez ${ }^{2}$ Jaime Huamaní Parra ${ }^{2}$ Ana Barreto Almea $^{3}$}

Residente del 4to año de la Especialidad de Cirugía Buco-Maxilofacial Facultad de Estomatología, Universidad Peruana Cayetano Heredia. Lima, Perú.

2 Especialista y Asistente del Servicio de Cirugía Oral y Maxilofacial, Hospital Nacional Cayetano Heredia Lima, Perú.

3 Especialista en Cirugía Buco-Maxilofacial, Facultad de Estomatología Universidad Peruana Cayetano Heredia. Lima, Perú

\section{Correspondencia:}

David Moreno Villalobos

Calle La Victoria 115, Urb. Ingeniería. San Martín de Porres

Lima, Perú

E-mail: david.moreno.v@hotmail.com

\title{
Osteomielitis mandibular por actinomices: Reporte de caso
}

Moreno-Villalobos $D^{\prime}$, Paniura-Rodríguez $D^{2}$, Huamani-Parra $J^{2}$, Barreto-Almea $A^{3}$. Osteomielitis mandibular por actinomices. Rev Estomatol Herediana. 2012 Oct-Dic;22(4):223-7.

\section{RESUMEN}

Se reporta el caso de un paciente varón de 27 años con antecedente de exodoncia compleja de la tercera molar mandibular inferior derecha que presentaba una tumefacción circunscrita dolorosa en la región submandibular ipsilateral. En el estudio imaginológico, la radiografía panorámica presentaba un proceso osteolítico periapical e interradicular con un patrón osteogénico circundante por lo que se utilizó como complemento una tomografía cone beam, en donde se evidenció compromiso desde la rama mandibular derecha hasta la sínfisis mandibular. Las lesiones a nivel de tejidos blandos y tejidos duros fueron diagnosticadas y manejadas como una actinomicosis cervicofacial y osteomielitis crónica supurativa respectivamente. El conocimiento de las diferentes infecciones bacterianas, un adecuado análisis clínico y estudio imaginológico nos darán la pauta para la correcta terapéutica de las distintas patologías maxilofaciales.

Palabra clave: ACTINOMICOSIS CERVICOFACIAL, OSTEOMIELITIS, INFECCIONES BACTERIANAS.

Mandibular osteomyelitis by actinomyces: Case report

\section{ABSTRACT}

A Case of a 27-years old male with a history of complex extraction of right mandibular third molar that had a painful circumscribed swelling in the ipsilateral submandibular region. In imaging studies, the ortopantograph showed a periapical and interradicular osteolytic process with a osteogenic pattern surrounding, so we used a Cone beam Tomography as complement where we found commitment from the right ramus to the mandibular symphsis. Damage at soft and hard tissue were diagnosed and managed as a cervicofacial actinomycosis and supurative chronic osteomyelitis respectively. The knowledge of different bacterial infections, appropriate clinical analysis and imaging studies will lead us to the correct therapy of various maxillofacial pathologies

Key words: ACTINOMYCOSIS, CERVICOFACIAL, OSTEOMYELITIS, BACTERIAL INFECTIONS

\section{Introducción}

$\mathrm{La}$ actinomicosis es una enfermedad crónica generalmente caracterizada por la formación de abscesos, trayectos fistulosos y fibrosis de los tejidos. Es causada por una de las 5 especies de Actinomices patógenas para el ser humano. La infección cervicofacial es la manifestación más común de la enfermedad ocupando aproximadamente el $50 \%$ de los casos, seguida de la afección al sistema nervioso central, pulmones, pared torácica, órganos abdominales y pélvicos. $\mathrm{La}$ infección es usualmente precedida por una infección dental o trauma oromaxilofacial (1).

Los actinomices son organismos gram $(+)$ anaerobios o microaerofilicos con apariencia de hifas o fi- lamentos al examen microscópico, siendo habitantes comunes de la cavidad oral y regiones faríngeas pueden ser aisladas a partir de la criptas tonsilares, placa dental, dentina cariada, margen gingival, fluido crevicular y bolsas periodontales (2).

Fue descrita originalmente en 1878 por Israel y Wolfe, quienes aislaron el organismo y definieron su naturaleza anaerobia. Los humanos son el único reservorio para las especies causantes de enfermedad cervicofacial. La actinomicosis tiene distribución mundial sin predilección por raza, edad u ocupación. Por razones que aún son desconocidas la predominancia masculina de 3:1 se reporta en muchas publicaciones La enfermedad ocurre por invasión directa y raramente por di- seminación hematógena o metastásica. La bacteria tiene la tendencia de diseminarse sin respetar barreras anatómicas (3).

Clínicamente, se presenta como una infección persistente y crónica con induración y nodularidad asintomática debido a la fibrosis con intermitentes y espontáneas zonas de drenaje. Una variación es el hallazgo meses o años después de la exodoncia de un diente posterior en la limitación de la apertura por la fibrosis de uno de los músculos masticatorios o focos de infección crónicos localizados profundamente. Menos común se puede presentar como una infección aguda supurativa con una masa fluctuante de rápida progresión y naturaleza piogénica $(1,3)$. 
Las lesiones se caracterizan por un desarrollo lento en semanas a meses con adherencia a la piel subyacente de apariencia azulada o rojiza, por lo que es usualmente confundida con celulitis o congestión venosa. Con el tiempo hay formación de tractos fistulosos en la superficie de la piel o mucosa, eventualmente con salida de exudado amarillo-seroso calcificado que proporciona las características de los gránulos de azufre (4).

La actinomicosis también puede comprometer estructuras óseas causando osteítis u osteomielitis. La osteomielitis por actinomicosis ha sido reportada infrecuentemente en adultos. El compromiso óseo ocurre del 1 al 15\% de los casos (Lewis y cols.), probablemente debido a una diseminación hematógena del actinomices con la formación de granulomas intra-oseos y reacción sub-perióstica mínima (5).

Histológicamente se evidencia gránulos de tamaño variable formados por colonias de Actinomices, si son los suficientemente grandes pueden tener un color amarillo dando el patrón típico de gránulos de azufre. Rodeando a los neutrófilos se encuentra usualmente tejido de granulación, tejido fibroso, capilares y células plasmáticas, linfocitos y ocasionalmente macrófagos espumosos. Las lesiones de mayor tiempo mostrarán mayor fibrosis y disminución de los componentes inflamatorios $(6,7)$.

La confirmación diagnóstica requiere de recuperar las diferentes especies de Actinomices de un espécimen adecuadamente cultivado, típicamente por aspiración con aguja fina (PAF) de un absceso, fistula o de un espécimen largo de biopsia. Las muestras obtenidas deben ser bien manejadas para evitar la contaminación por la flora oral normal y ser sometidas a tinción Gram y a cultivos aerobios y anaerobios en pocos minutos para asegurar la adecuada identificación de la especie bacteriana (8).

En este trabajo se reporta un caso de Actinomicosis cervicofacial como secuela de una exodoncia de tercer molar inferior derecho, además de osteomielitis mandibular supurativa posiblemente generada por el mismo patógeno. Se presentan las características clínica, imaginologicas, histológicas y esquemas de tratamiento para cada patología recalcando la importancia de mejorar los métodos de diagnóstico para poder correlacionar ambas entidades.

\section{Reporte de caso}

Paciente de sexo masculino de 27 de edad que acude al servicio de Cirugía Oral y Maxilofacial del Hospital Nacional Cayetano Heredia, por presentar un aumento de volumen circunscrito, eritematoso, ligeramente doloroso y renitente a la palpación, localizado en la región submandibular derecha con antecedente de exodoncia de tercera molar inferior del mismo lado de hace 1 mes. (Figuras 1 y 2).

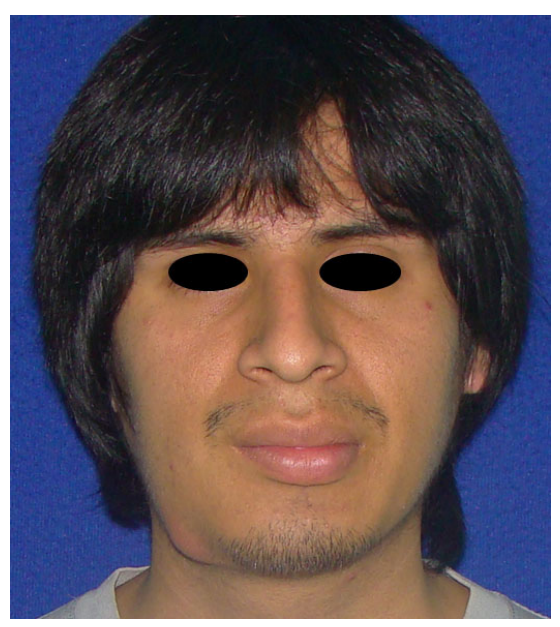

Fig. 1 Vista frontal extraoral.

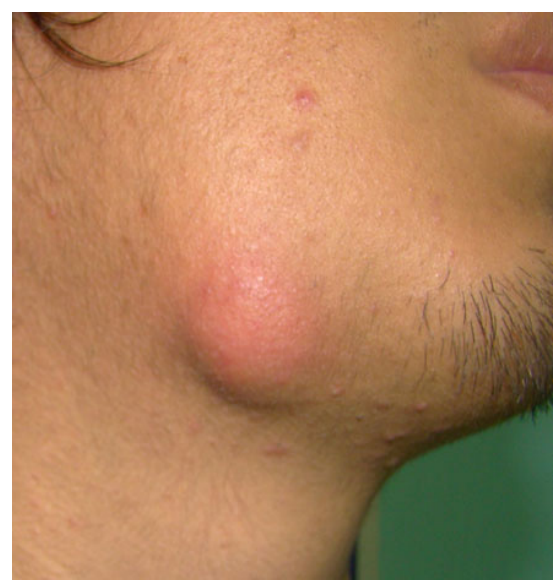

Fig. 2 Tumefacción submandibular.

A la evaluación intraoral, borramiento del fondo de surco que se extiende desde zona del tercer molar hasta sínfisis mandibular sin variaciones en su consistencia, encía adherida adyacente con variación en su superficie y coloración sin salida de secreciones (Fig. 3 y 4).

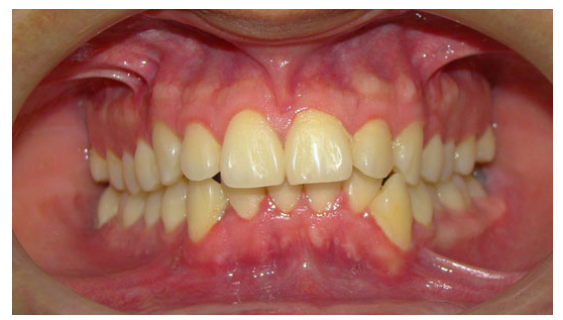

Fig. 3 Vista frontal intraoral.

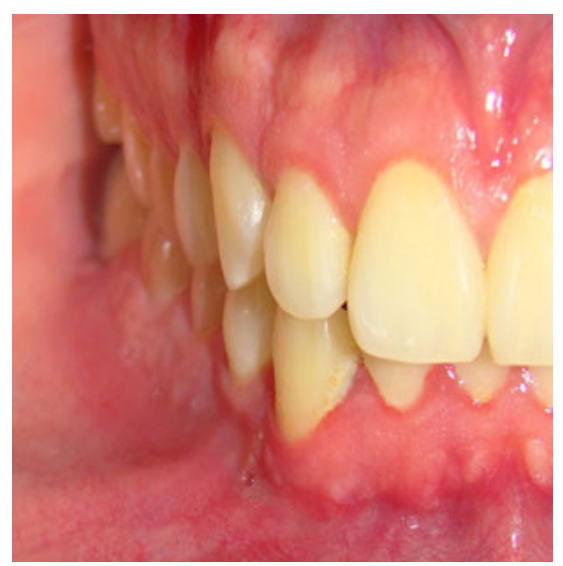

Fig. 4 Borramiento de fondo de surco.

La radiografía panorámica mostraba a nivel de la pieza 4.7 ensanchamiento del espacio del ligamento periodontal, proceso osteolítico periapical e interradicular de origen 
a determinar con proceso osteogéncio circundante además se observa lesiones osteolíticas a nivel del cuerpo mandibular. Las demás estructuras óseas y dentarias presentaban de características normales (Fig. 5).

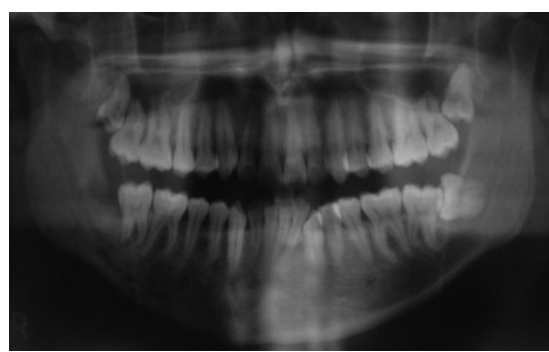

Fig. 5 Radiografia panorámica

El hemograma completo solicitado para complementar el plan de trabajo para el diagnóstico no mostró valores fuera de los rangos normales probablemente debido a la cronicidad de la lesión.

Las características clínicas, radiográficas y de laboratorio nos condujeron a pensar en una probable infección por actinomicosis por lo que se procede a realizar el drenaje del absceso en el que se obtuvo $10 \mathrm{cc}$ de secreción hematopurulenta y los típicos gránulos de azufre los cuales fueron enviados a estudio anatomopatologico, (Fig. 6).

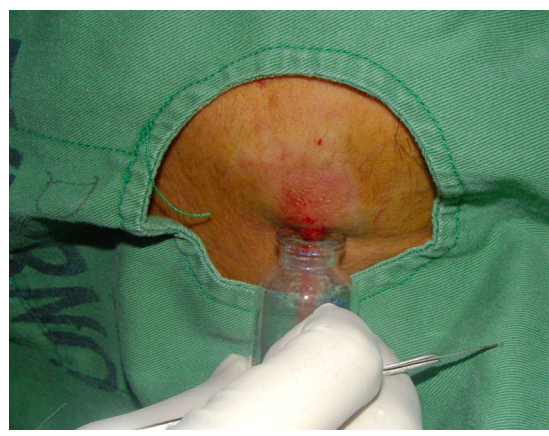

Fig. 6 Drenaje de absceso cutáneo.st

En el estudio histopatológico se evidenció colonias de microorganismos filamentosos dispuestos en forma radial con una parte central basofílica y eosinofílica periférica, rodeadas por abundante cantidad de polimorfonucleares y zonas de histiocitos espumosos asociado a un absceso actinomicotico (Fig. 7 y 8).

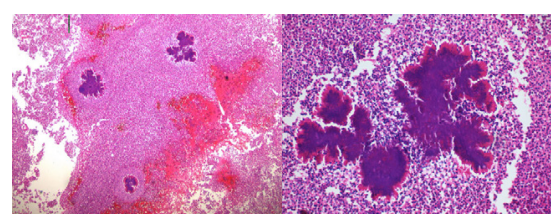

Fig. 7 y 8. Microfotografía del abceso por actinomicosis.

El tratamiento farmacológico dado fue a base de fenoximetilpenicilina 1 millon de U.I, 2 tabletas cada 8 horas por tiempo prolongado (4-6 meses aproximadamente).

Debido a los hallazgos encontrados en la radiografía panorámica, se solicitó una tomografía Cone Beam en donde se evidenció la presencia de imágen hiperdensa con áreas hipodensas localizadas en la parte posterior del cuerpo mandibular derecho y tercio inferior de la rama de limites mal definidos que compromete hueso esponjoso y ambas tablas óseas, también presenta áreas con reacción periostal por vestibular. Las lesiones se extienden hasta el sector anteroinferior sin cruzar la línea media causando perforación de la tabla vestibular (Fig. 9,10 y 11).

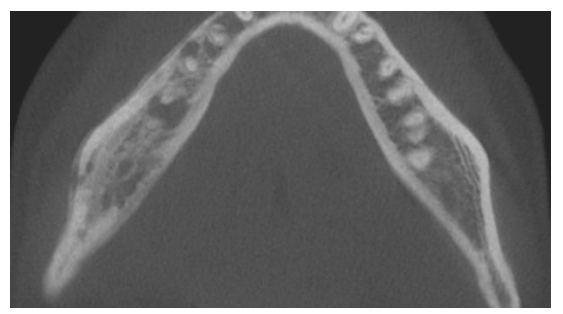

Fig. 9 Corte axial tomográfico: Lesiones en cuerpo mandibular derecho.

El análisis de los estudios imaginológicos integrados a las características clínicas condujo a plantear el diagnóstico de Osteomielitis mandibular por actinomicosis por lo que se solicitó exámenes pre-

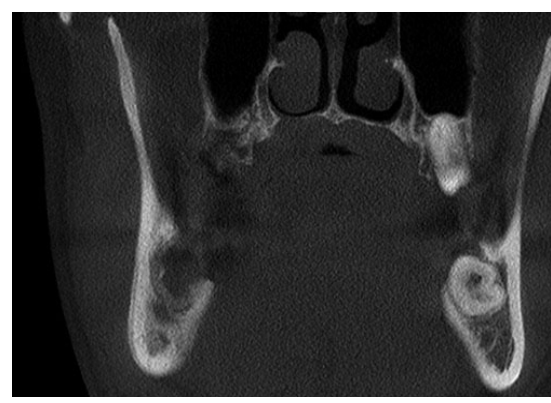

Fig. 10 Corte coronal en la TAC.

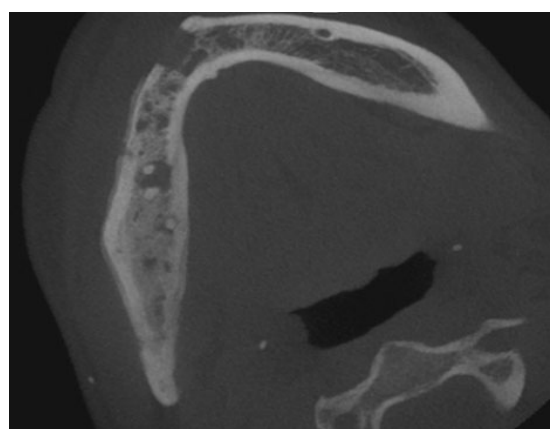

Fig. 11 Perforación de tabla ósea vestibular.

quirúrgicos para realizar el procedimiento quirúrgico bajo anestesia general.

En sala de operaciones se realizó curetaje del tejido óseo infectado y exodoncia de la pieza 3.7 (Fig. 12), las muestras obtenidas fueron enviadas a examen anatomatoplatologico arrojando como diagnóstico osteomielitis crónica supurativa caracterizado por trabéculas de hueso esponjoso rodeadas por tejido conectivo fibroso con infiltrado inflamatorio constituido por linfocitos, células plasmáticas, histiocitos espumosos y polimorfonucleares entremezclados (Fig. 13).

Basados en todas las características presentadas por el paciente se

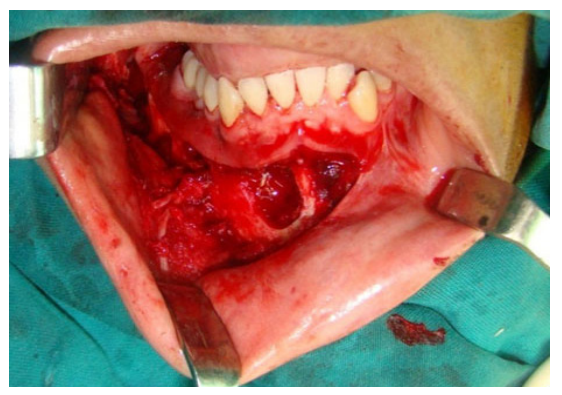

Fig. 12 Tratamiento quirúrgico. 


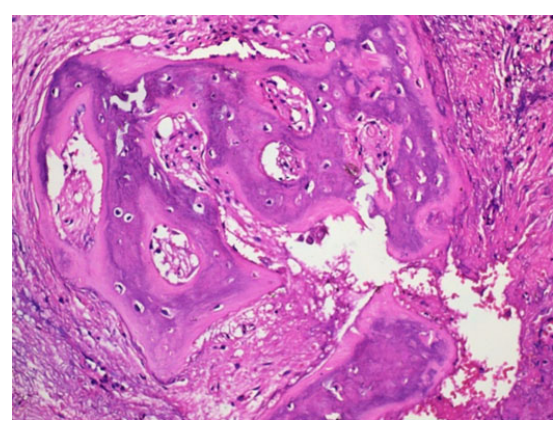

Fig. 13 Microfotografia de hueso comprometido.

estableció el diagnóstico de una osteomielitis crónica supurativa con abscesos actinomicoticos (Osteomielitis actinomicotica).

Se continuó con la terapéutica administrada previamente y se indicó 10 sesiones con oxígeno hiperbárico para mejorar el hábitat tanto extra e intraoral y potenciar el efecto reparativo. Actualmente el paciente es controlado en el servicio en donde se evidencia claramente la buena evolución (Figuras 14, 15, $16,17,18$ y 19$)$.

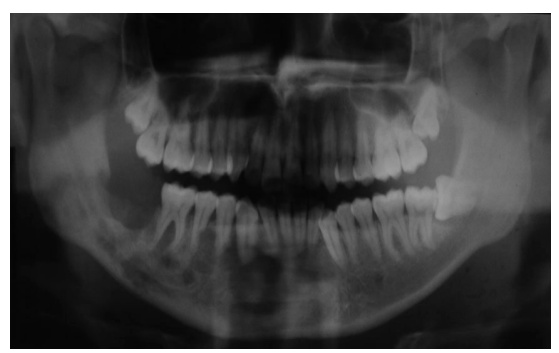

Fig. 14 Radiografía panoramica post operatoria inmediata.

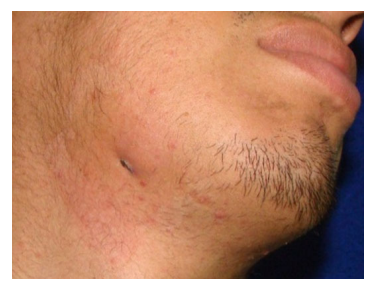

Fig. 15 Control 1 mes vista extraoral.

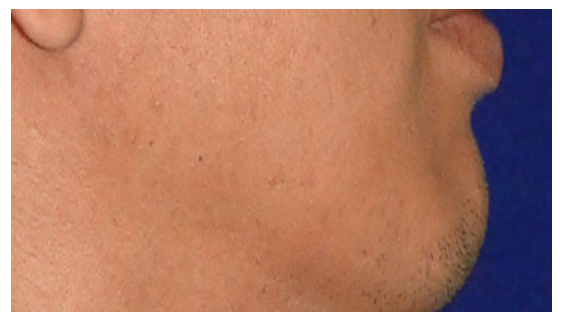

Fig. 16 Control 1 año vista extraoral.

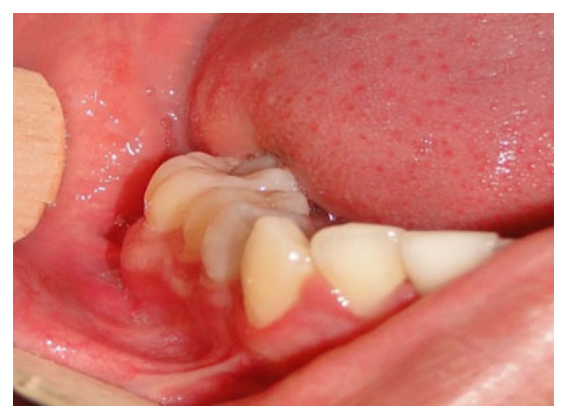

Fig. 17 Control 1 año vista intraoral.

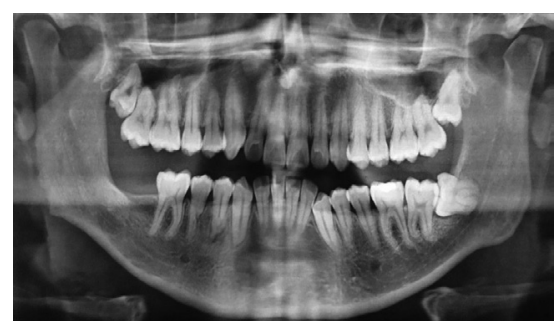

Fig. 18 Radiografia panorámica: Control 1 año.

\section{Discusión}

El actinomices requiere de un ecosistema polimicrobiano y trauma tisular para proliferar y crear la infección clínicamente evidente. Esta microflora actúa sinérgicamente para destruir el tejido aerobio vascularizado y producir el tejido de granulación pobremente oxigenado que se convierte en un ambiente que beneficia el crecimiento y la multiplicación del actinomices. La severidad y la cronicidad del trauma de los tejidos son factores que potencian el desarrollo de crecimiento anaerobio por estos organismos los cuales usualmente muestra baja virulencia $(10,11)$.

A pesar de que la historia y el examen físico son siempre básicos para el diagnóstico, el proceso natural de la infección actinomicotica indolente pero progresiva requiere de un alto índice de sospechas clínicas por lo cual muchas veces la infección por actinomices conlleva a un dilema de diagnóstico. Las radiografías pueden ser útiles para reconocer la extensión del proceso óseo pero no son específicas para la actinomicosis aun en la presencia de tumefacción de tejidos blandos y tractos sinusales. En el presente caso debido al hallazgo en la radiografía panorámica complementamos el estudio imaginológico con la tomografía cone beam, la cual nos permite una mejor evaluación de la extensión de la enfermedad, la reacción y compromiso de las corticales óseas $(1,7,12)$.

La confirmación diagnóstica depende de un cuidadoso cultivo de este anaerobio de preferencia cuando el paciente ha recibido antibióti$\cos$ de 7 a 10 días. Este cultivo puede ser recolectado directamente del drenaje del tracto sinuoso o la biopsia del tejido o después de la aspiración con aguja. Aun con las precauciones, la recolección del patógeno comúnmente fracasa, usualmente en más del $50 \%$ de los casos esto asociado a medicación antibiótica previa, crecimiento de organismos concomitantes o metodología inadecuada. Todos los cultivos deben ser transportados inmediatamente al laboratorio microbiológico en un medio no anaerobio con atmosferas de dióxido de carbono. Los agares deben ser incubados al menos 14 días bajo completas condiciones anaerobias en una atmosfera al 5\% de dióxido de carbono a $37^{\circ} \mathrm{C}$. Las muestras obtenidas tanto en el drenaje como en el curetaje solo fueron enviadas a exámenes anatomopatologicos debido a la escasez de recursos y falta de medios de cultivo disponibles $(13,14)$.

Las distintas especies de actinomicosis son susceptibles a muchos antibióticos in vitro. La experiencia clínica apoya el uso de penicilina $\mathrm{G}$ como la droga de elección y para evitar la recurrencia es recomendable el uso prolongado. La terapia recomendada es de altas dosis de 18 a 24 millones de unidades 
diarias de penicilina por un largo periodo de 2 a 6 semanas seguida por una terapia oral completando 6 a 12 meses. La mayoría de casos en el servicio son manejados con terapia antibiótica vía oral de larga duración de 2 a 6 meses con resultados exitosos. Cabe resaltar que la terapia antibiótica tiene que ser administrada en conjunto con el tratamiento quirúrgico en base al drenaje y exploración para el éxito del tratamiento porque la bacteria al encontrarse en un medio avascular y rodeado de tejido fibrotico hace imposible la llegada adecuada del antibiótico $(1,2,14)$.

\section{Referencias Bibliográficas}

1. Miller M, Haddad A. Cervicofacial actinomycosis. Oral Surg Oral Med Oral Pathol Radiol Endod. 1998;85:496-508.

2. Schaal K, Lee H. Actinomycete infections in humans-a review. Gene. 1992;115:201-11.

3. Lerner P. The lump jaw. Cervicofacial actinomycosis. Infect Dis Clin North Am. 1988;2(1):203-20.
4. Sharkawy A. Cervicofacial actinomycosis and mandibular osteomyelitis. Infect Dis Clin N Am. 2007;21:543-56.

5. Chow A. Infection of the oral cavity, neck and head. En Mandell G, Bennet J, Dolin R. Principles of practice of infectious diseases. 6th edition. Philadelphia: Churchill Linvingstone; 2005.p. 787-98.

6. Martin M. Antibiotic treatment of cervicofacial actinomycosis for patients allergic to penicillin a clinical and in vitro study. British Journal of Oral and Maxillofacial Surgery. 1985;23:428-34.

7. Walker S, Middelkamp J, Sclaroff A. Mandibular osteomyelitis caused by actinomyces israelii. Oral Surg Oral Med Oral Pathol. 1981;51(3):243-4.

8. Acevedo F, Baudrand R, Letelier L, Gaete P. Actinomycosis: a great pretender. Case reports of unusual presentations and a review of the literature. International Journal of Infectious disease. 2008;12:358-62.
9. Yakata H, Nakajima T, Yamada $\mathrm{H}$, Tokiwa N. Actinomycotic osteomielitis of the mandible: Report of Case. J Oral Surg. 1978; 36:720-24.

10.Holst E. Cervicofacial actinomycosis. A retrospective study. Int J Oral Surg 1979;8:194-8.

11. Norman JE. Cervicofacial actinomycosis. Oral Surg Oral Med Oral Pathol. 1970;29(5):735-45.

12.Gupta D, Gupta M, Naidu N. Mandibular osteomyelitis caused by Actinomyces Israelii. Report of a case.. J Maxillofac Surg. 1986;14(5):291-3.

13. Hall V. Actinomyces - Gathering evidence of human colonization and infection. Anaerobe 2008;14:1-7.

14.Kaplan I, Anavi K, Anavi Y, et al. The clinical spectrum of Actinomyces-associated lesions of the oral mucosa and jawbones: correlations with histomorphometric analysis. Oral Surg Oral Med Oral Pathol Oral Radiol Endod 2009;108(5):738-46. 